\title{
Commentary: Scylla versus Charybdis: The eternal dilemma continues
}

\author{
Vivek Rao, MD, PhD
}

\author{
From Cardiovascular Surgery, Peter Munk Cardiac Centre, Toronto General Hospital, Toronto, Ontario, Canada. \\ Disclosures: Author has nothing to disclose with regard to commercial support. \\ Received for publication July 30, 2018; accepted for publication July 31, 2018 \\ Address for reprints: Vivek Rao, MD, PhD, Cardiovascular Surgery, Peter Munk Cardiac Centre, Toronto General \\ Hospital, 200 Elizabeth St, Toronto, ON, Canada M5G2C4 (E-mail: vivek.rao@uhn.ca). \\ J Thorac Cardiovasc Surg 2019;158:206-7 \\ $0022-5223 / \$ 36.00$ \\ Copyright (c) 2018 by The American Association for Thoracic Surgery \\ https://doi.org/10.1016/j.jtcvs.2018.07.092
}

Anticoagulation has long been viewed as a double-edged sword. In patients at high risk for thromboembolic (TE) events, anticoagulation with vitamin $\mathrm{K}$ antagonists such as warfarin or the newer "novel" oral anticoagulants (NOACs) has proven to be effective in reducing neurologic events. However, even the NOACs have bleeding complications as a notable side effect to therapy, and thus their use in patients with mechanical heart valves was discontinued.

Patients with mechanical heart valves are a particularly challenging patient population because they tend to be young when then receive their valves. Inevitably, as they age they are at risk for common afflictions that often require surgical intervention. These interventions can be elective, such as routine orthopedic procedures or emergency procedures in patients with acute abdominal pain. The perioperative management of mechanical valve anticoagulation for noncardiac surgery has never been well standardized.

In this issue of the Journal, Tan and colleagues ${ }^{1}$ have provided an expert commentary describing the evidence (or lack thereof) around bridging versus nonbridging strategies. Their Figure 1 is a nice pictoral illustration of the "art and science" that becomes necessary when managing anticoagulation in patients with mechanical heart valves.

A recent observational study from Italy provided some reassuring data. ${ }^{2}$ In a cohort of more than 2350 patients in the Italian Federation of Anticoagulation Clinics, the overall rate of TE events was only 0.67 per 100 patient years. In contrast, the bleeding risk was slightly higher at 1.0 major bleeds per 100 patient years. Of note, the adequacy of anticoagulation (as measured by the time in therapeutic range) did not influence the occurrence of TE. Rather, patient factors such as atrial fibrillation, a history of TE, and a mitral prosthesis were found to be predictive of events. This report further supports the recommendations of Tan and colleagues, ${ }^{1}$ who argue for patient-specific management of anticoagulation considering the clinical risk factors and the bleeding risk of the proposed intervention.

It is thought provoking to realize that even in the absence of anticoagulation, the risk of a TE event with a mechanical

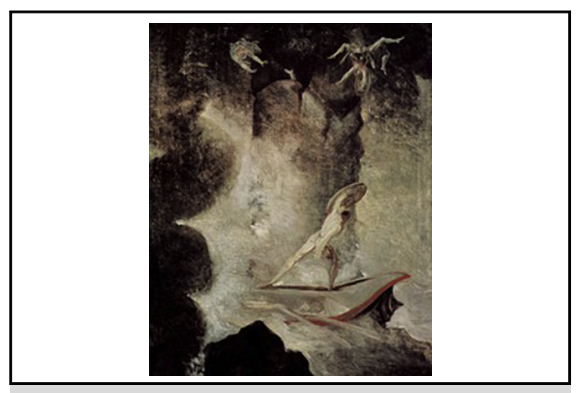

Odysseus in front of Scylla versus Charybdis by Heinrich Fuseli (1796 Aargauer Kunsthaus).

\section{Central Message}

The management of perioperative anticoagulation in patients with mechanical heart valves is not well standardized. The TE risk appears lower than the risk of major bleeding.

See Article page 200

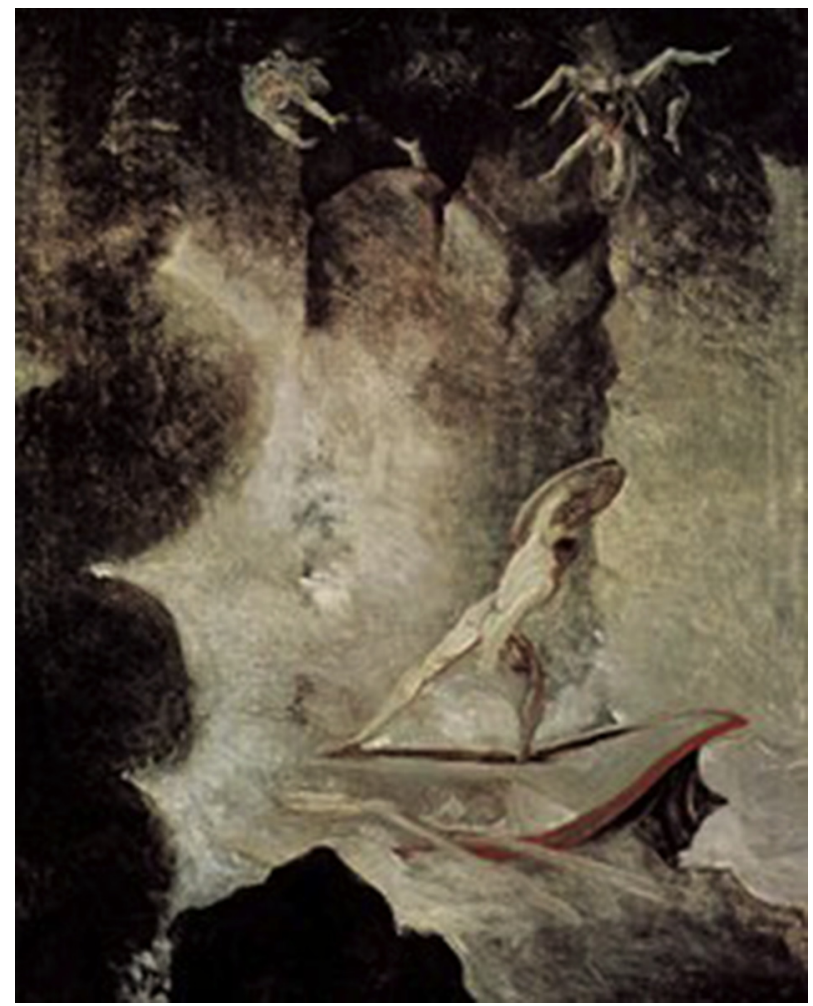

FIGURE 1. Odysseus in front of Scylla versus Charybdis by Heinrich Fuseli (1796 Aargauer Kunsthaus). 
aortic valve ranges from $6 \%$ to $22 \%{ }^{3}$ Therefore, even at a $22 \%$ risk, the daily risk of TE without anticoagulation is $0.06 \%$. Considering that we typically hold warfarin 3 days before elective surgery and resume it on postoperative day 1 , the cumulative TE risk remains $0.24 \%$. Clearly, patient factors may increase or decrease this risk, but the point is the risk is small compared with a potential lifethreatening bleeding complication after major surgery.

In a trial of patients with atrial fibrillation, Douketis and colleagues $^{4}$ found no benefit to perioperative bridging. Although these patients are at lower risk of TE complications compared with those with mechanical heart valves, it provides limited evidence of the lack of efficacy of short-term bridging before elective surgery.

As with Odysseus' choice between the serpent Scylla or the whirlpool Charybdis (Figure 1), every patient with a mechanical heart valve faces the risk of TE versus bleeding when contemplating a surgical procedure. As pointed out in their Discussion, the field is really in need of prospective data to guide our therapeutic choices. In the interim, the proposed strategy appears logical and would be a useful addition to any anticoagulation clinic.

\section{References}

1. Tan CW, Wall M, Rosengart TK, Ghanta RK. How to bridge? Management of anticoagulation in patients with mechanical heart valves undergoing noncardiac surgery procedures. J Thorac Cardiovasc Surg. 2019;158:200-3.

2. Poli D, Antonucci E, Pengo V, Migliaccio L, Testa S, Lodigiani C, et al Mechanical prosthetic heart valves: quality of anticoagulation and thromboembolic risk. The observational multicenter PLECTRUM study. Int J Cardiol. 2018;267:68-73.

3. Nishimura RA, Otto CM, Bonow RO, Carabello BA, Erwin JP III, Fleisher LA, et al. 2017 AHA/ACC focused update of the 2014 AHA/ACC guideline for the management of patients with valvular heart disease: a report of the American College of Cardiology/American Heart Association task force on clinical practice guidelines. J Am Coll Cardiol. 2017;70:252-89.

4. Douketis JD, Spyropoulos AC, Kaatz S, Becker RC, Caprini JA, Dunn AS, et al. Perioperative bridging anticoagulation in patients with atrial fibrillation. $N$ Engl J Med. 2015;373:823-33. 